\title{
Influence of surgical strategies on outcome after the Norwood procedure
}

\author{
Massimo Griselli, MD, MS, FRCS (CTh), a Simon P. McGuirk, BMedSci (Hons), MRCS (Ed), , Oliver Stümper, MD, PhD, \\ Andrew J. B. Clarke, MBBS, FRACS, ${ }^{a}$ Paul Miller, MRCP, ${ }^{\mathrm{b}}$ Rami Dhillon, MRCP, MRCPCH, ${ }^{\mathrm{b}}$ John G. C. Wright, MA, FRCP,

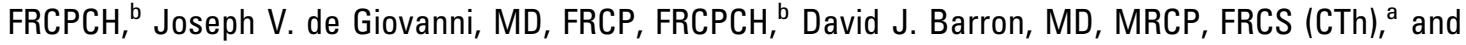 \\ William J. Brawn, FRCS, FRACS ${ }^{a}$
}

From the Departments of Pediatric Cardiac Surgery and Pediatric Cardiology, Diana, Princess of Wales Children's Hospital, Birmingham, United Kingdom.

Read at the Eighty-fifth Annual Meeting of The American Association for Thoracic Surgery, San Francisco, Calif, April 10-13, 2005.

Received for publication April 4, 2005; revisions received Aug 10, 2005; accepted for publication Aug 15, 2005.

Address for reprints: William J. Brawn, FRCS, FRACS, Consultant Cardiac Surgeon, Department of Pediatric Cardiac Surgery, Diana, Princess of Wales Children's Hospital, Steelhouse Lane, Birmingham, B4 6NH, United Kingdom (E-mail: william.brawn@bch.nhs.uk).

J Thorac Cardiovasc Surg 2006;131:418-26 $0022-5223 / \$ 32.00$

Copyright () 2006 by The American Association for Thoracic Surgery

doi:10.1016/j.jtcvs.2005.08.066
Objective: The study objective was to identify how the evolution of surgical strategies influenced the outcome after the Norwood procedure.

Methods: From 1992 to 2004, 367 patients underwent the Norwood procedure (median age, 4 days). Three surgical strategies were identified on the basis of arch reconstruction and source of pulmonary blood flow. The arch was refashioned without extra material in group A $(\mathrm{n}=148)$. The arch was reconstructed with a pulmonary artery homograft patch in groups $B(n=145)$ and $C(n=74)$. Pulmonary blood flow was supplied by a modified Blalock-Taussig shunt in groups A and B. Pulmonary blood flow was supplied by a right ventricle to pulmonary artery conduit in group C. Early mortality, actuarial survival, and freedom from arch reintervention or pulmonary artery patch augmentation were analyzed.

Results: Early mortality was $28 \%(\mathrm{n}=102)$. Actuarial survival was $62 \% \pm 3 \%$ at 6 months. Early mortality was lower in group C (15\%) than group A (31\%) or group $\mathrm{B}(31 \% ; P<.05)$. Actuarial survival at 6 months was better in group C $(78 \% \pm 5 \%)$ than group A $(59 \% \pm 5 \%)$ or group B $(58 \% \pm 4 \% ; P<.05)$. Fifty-three patients (14\%) had arch reintervention. Freedom from arch reintervention was $76 \% \pm 3 \%$ at 1 year, with univariable analysis showing no difference among groups $\mathrm{A}, \mathrm{B}$, and $\mathrm{C}$ $(P=.71)$. One hundred patients $(27 \%)$ required subsequent pulmonary artery patch augmentation. Freedom from patch augmentation was $61 \% \pm 3 \%$ at 1 year, and was lower in group C $(3 \% \pm 3 \%)$ than group A $(80 \% \pm 4 \%)$ or group B $(72 \% \pm 5 \%$; $P<.05)$.

Conclusions: Survival after the Norwood procedure improved after the introduction of a right ventricle to pulmonary artery conduit, but a greater proportion of patients required subsequent pulmonary artery patch augmentation. The type of arch reconstruction did not affect the incidence of arch reintervention.

$\mathrm{H}$ ypoplastic left heart syndrome (HLHS) refers to a spectrum of congenital cardiac abnormalities that are characterized by severe stenosis or atresia of the mitral and aortic valves, a diminutive ascending aorta, and left ventricular hypoplasia. ${ }^{1}$ Coarctation is usually associated with this lesion and contributes to reduce retrograde blood flow into the ascending aorta. ${ }^{2}$ The left ventricle is unable to support the systemic circulation, which must be maintained by the right ventricle through a patent ductus arteriosus. HLHS accounts for $2.5 \%$ of congenital heart defects but is responsible for up to $25 \%$ of all deaths from congenital heart defects within the first week of life. ${ }^{3}$ Without surgical palliation, $95 \%$ of children with HLHS die within the first month of life. ${ }^{4}$

More than 20 years ago Dr Norwood reported the first successful surgical palliation of HLHS. ${ }^{5,6}$ The first stage of this surgical palliation is now commonly 


$$
\begin{aligned}
& \text { Abbreviations and Acronyms } \\
& \begin{aligned}
\text { CI } & =\text { confidence interval } \\
\text { CPA } & =\text { central pulmonary artery } \\
\text { HLHS } & =\text { hypoplastic left heart syndrome } \\
\text { LR } & =\text { likelihood ratio } \\
\text { MBTS } & =\text { modified Blalock-Taussig shunt } \\
\text { NP } & =\text { Norwood procedure } \\
\text { RV-PA } & =\text { right ventricle to pulmonary artery }
\end{aligned}
\end{aligned}
$$

called the Norwood procedure (NP). The aim of the NP is to establish unobstructed systemic and coronary blood flow from the right ventricle, and unobstructed pulmonary venous return across the atrial septum, and ensure adequate pulmonary blood flow without causing volume overload. Over the years, there has been a substantial improvement in the outcome after surgical palliation for HLHS. This has been attributed to refinements in the surgical technique and perioperative medical management care, together with a better understanding of the postoperative physiology. ${ }^{7}$

The success of the NP in HLHS has allowed the application of this procedure to other different pathologies, characterized by systemic outflow tract obstruction and functionally single ventricle anatomy. The early survival after the NP in contemporary series varies between $70 \%$ and $80 \%,{ }^{8-12}$ although an increasing number of centers have reported survivals of greater than $90 \%$ in the hospital. ${ }^{13-16}$

The aim of this study was to determine the influence of different surgical strategies and techniques used at our institution on outcome after the NP for all patients with classic HLHS or systemic outflow tract obstruction associated with either right or left ventricular hypoplasia, focusing particularly on aortic arch reconstruction and pulmonary blood flow supply.

\section{Patients and Methods}

Between November 1992 and August 2004, 367 patients with functionally single ventricle anatomy and systemic outflow tract obstruction underwent the NP at the Diana Princess of Wales Children's Hospital, Birmingham, United Kingdom. Most of the patients had a right ventricle-dependent systemic circulation $(\mathrm{n}=$ 333, 91\%; Table 1). The median age at operation was 4 days (range, 0-217 days). The majority $(\mathrm{n}=283,77 \%)$ underwent operation within the first 7 days, and only 19 (5.2\%) underwent operation at more than 30 days of age.

All operations were performed using deep hypothermic cardiopulmonary bypass with periods of circulatory arrest for arch reconstruction. Myocardial protection was provided using a single dose of cold crystalloid cardioplegia (St Thomas Hospital solution type $1,30 \mathrm{~mL} / \mathrm{kg}^{-1}$ ) administered through the side arm of the arterial cannula before circulatory arrest. Antegrade cerebral perfusion, introduced in September 2002, was used during arch reconstruction in all patients with head and neck vessels of adequate size to accommodate the arterial cannula. The remainder of the operative strategy remained unchanged throughout the study pe-
TABLE 1. Primary cardiac anatomy

\begin{tabular}{lrr}
\hline RV-dependent circulation & 333 & $90.7 \%$ \\
Classic hypoplastic left heart syndrome & 290 & \\
Unbalanced atrioventricular septal defect & 16 & \\
Double-outlet RV with mitral atresia & 15 & \\
Critical aortic stenosis with hypoplastic LV & 6 & \\
Double-inlet, double-outlet RV & 3 & \\
Mitral atresia with aortic arch hypoplasia & 3 & \\
LV-dependent circulation & 34 & $9.3 \%$ \\
Double-inlet LV with D-TGA & 20 & \\
Tricuspid atresia with D-TGA & 8 & \\
D-TGA, VSD with hypoplastic RV & 4 & \\
Other & 2 &
\end{tabular}

$R V$, Right ventricle; $L V$, left ventricle; D-TGA, dextro-transposition of great arteries; VSD, ventriculoseptal defect.

riod, as previously described. ${ }^{17}$ In particular, neither modified ultrafiltration nor aprotinin was used during surgery. The median duration of cardiopulmonary bypass, aortic crossclamp, and deep hypothermic circulatory arrest times were 71 minutes (range, 17323 minutes), 51 minutes (range, 0-109 minutes), and 55 minutes (range, 0-121 minutes), respectively. The median period of cardiopulmonary support (ie, cumulative duration of cardiopulmonary bypass and deep hypothermic circulatory arrest) was 121 minutes (range, 20-414 minutes). The atrial septum was excised through the atrial cannulation site. Arch reconstruction was performed using 1 of 2 established techniques. The original technique involved arch reconstruction without the use of additional patch material, as previously reported by this institution ${ }^{18,19}$ and described by Fraser and Mee. ${ }^{20}$

All the duct tissue was excised from the aorta, disconnecting the descending aorta from the arch. The aortic arch was opened along the inner aspect of the ascending aorta, down to the level of the transected proximal pulmonary artery. A complex DamusKaye-Stansel anastomosis was then constructed between the aortic arch, proximal pulmonary artery, and descending aorta (Figure 1, A).

The second technique, which has been used exclusively since April 1999, involved arch reconstruction with a pulmonary homograft patch, as originally described by Jonas and colleagues ${ }^{21}$ with some variations. The duct tissue was completely excised only in the presence of severe coarctation, leaving the aortic back wall in continuity in all the other cases.

The arch was open in the inner aspect of the ascending aorta. The incision extended as proximally as possible to allow optimal coronary perfusion, and distally well beyond the coarctation area. The arch was then reconstructed with pulmonary homograft material cut to a teardrop shape. The proximal pulmonary artery was then anastomosed to a longitudinal incision in the allograft patch on the underside of the reconstructed neoaorta (Figure $1, B$ ). In those patients in whom the coarctation tissue was excised, the back wall of the distal aortic arch and proximal descending aorta are joined directly, and then the underside of the neoaortic arch is augmented with allograft material.

Pulmonary blood flow was established using a modified Blalock-Taussig shunt (MBTS) $(\mathrm{n}=293,80 \%)$ or a right ventricle-pulmonary artery (RV-PA) conduit $(n=74,20 \%)$. The MBTS consisted of a polytetrafluoroethylene tube conduit (Gore- 
A

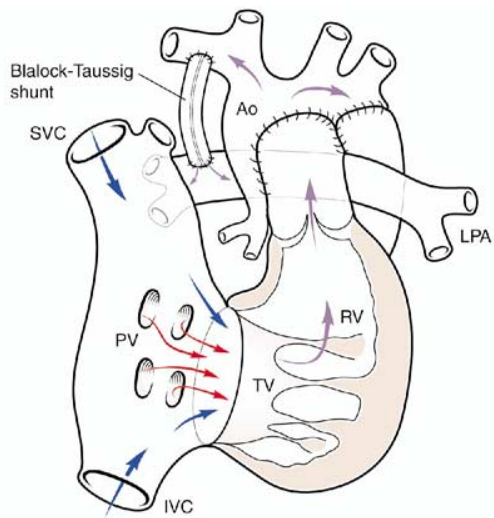

B

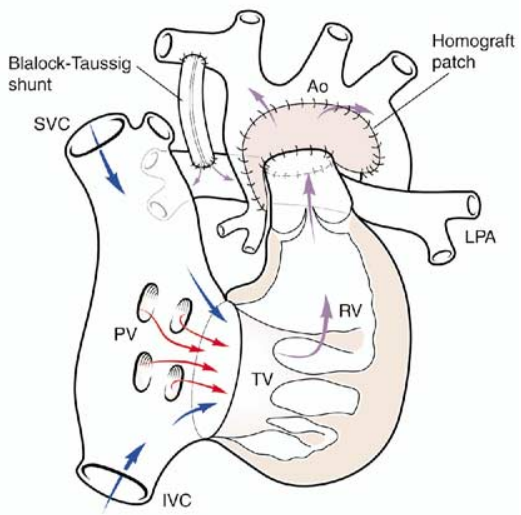

Figure 1. Norwood procedure with modified Blalock-Taussig shunt (MBTS). A, Aortic arch reconstructed without additional material. B, Aortic arch reconstructed with additional pulmonary homograft patch. SVC, Superior vena cava; IVC, inferior vena cava; $A o$, aorta; $L P A$, left pulmonary artery; $R V$, right ventricle; $T V$, tricuspid valve; $P V$, pulmonary valve.

Tex, WL Gore \& Associates UK Ltd, Livingston, Scotland) running from the innominate artery to the upper border of the right pulmonary artery in almost all cases $(98 \%, \mathrm{n}=287)$ (Figure 1).

The majority of patients had a $3.5-\mathrm{mm}(59 \%, \mathrm{n}=173)$ or 3-mm MBTS (37.2\%, $\mathrm{n}=109)$, depending on whether the preoperative body weight was more or less than $2.5 \mathrm{~kg}$, respectively. A 4- or 5 -mm shunt was used in a few patients $(n=11)$. In patients in whom an MBTS was used, the central distal pulmonary artery defect was closed directly $(29 \%, \mathrm{n}=85)$ or by a patch $(71 \%, \mathrm{n}=$ 208) of different material (autologous pericardium, bovine pericardium, or pulmonary homograft).

The RV-PA conduit was introduced in March 2002. At first, the RV-PA conduit was taken to the left side of the ascending aorta, as described by Sano and colleagues ${ }^{22}$ and other series (Figure 2, A). ${ }^{23-25}$ In the last 51 cases performed at Birmingham Children's Hospital, the RV-PA conduit was passed on the right side of the ascending aorta (Figure 2, B). In this group of patients, the defect in the central distal pulmonary artery was closed by tailoring the distal end of the RV-PA conduit or by a separated patch. This technique has been used almost exclusively since February 2003. Sixty-eight patients $(92 \%)$ had a 5-mm RV-PA conduit, and 6 patients had a 4-mm RV-PA conduit, depending again on whether the preoperative body weight was more or less than $2.5 \mathrm{~kg}$, respectively.

On the basis of the type of arch reconstruction and source of pulmonary blood flow, 3 distinct surgical strategies were identi-
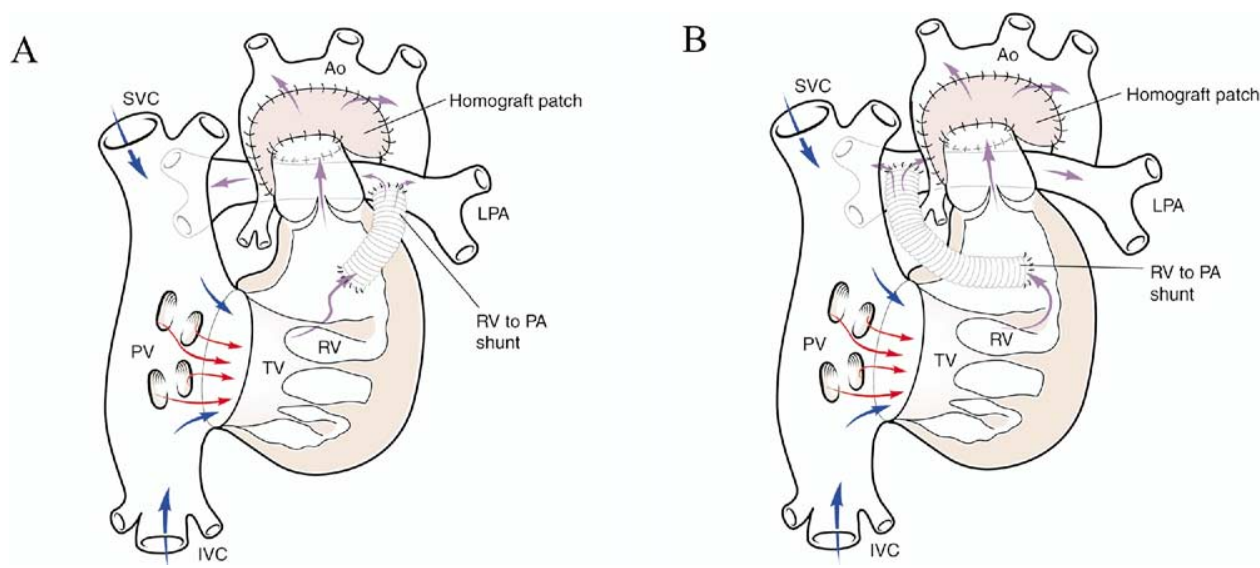

Figure 2. Norwood procedure with right ventricle-pulmonary artery (RV-PA) conduit. Aortic arch reconstructed with additional pulmonary homograft patch. A, RV-PA conduit passes to the left side of the neoaortic arch reconstruction. B, RV-PA conduit passes to the right side of the neoaortic arch reconstruction. SVC, Superior vena cava; IVC, inferior vena cava; $A$, aorta; $L P A$, left pulmonary artery; $R V$, right ventricle; $T V$, tricuspid valve; $P V$, pulmonary valve. 
fied. Between December 1992 and March 1999, the aortic arch was reconstructed without additional material and pulmonary blood flow was provided through an MBTS (group A, $n=148$ ). Between April 1999 and March 2002 (group B, n = 145), the aortic arch was reconstructed with a pulmonary homograft patch and pulmonary blood flow was supplied through an MBTS. Finally, between March 2002 and June 2004 (group C, n = 74), the aortic arch was reconstructed with a patch of pulmonary homograft and pulmonary blood flow was established using an RV-PA conduit.

For the purposes of this study, early mortality, actuarial survival, and actuarial freedom from arch reintervention and actuarial freedom from subsequent patch augmentation or catheter-based intervention of the central pulmonary arteries (CPAs) were used as outcome measures. These were analyzed using univariable and multivariable analyses.

This study involved the retrospective review of hospital records and echocardiographic and cardiac catheterization data, as well as assessment of the current clinical state. All patients have been followed up since discharge from the hospital by a pediatric cardiologist either in our own unit or in the patients' referring hospital. Follow-up was complete with a median interval of 22 months (range, 32 days-11.6 years).

\section{Statistical Analysis}

Data were examined by means of analysis of variance with a commercial statistical software package (SPSS for Windows, version 12; SPSS Inc, Chicago, Ill). Continuous variables are expressed as medians and ranges, and comparative univariable analyses were made with the Mann-Whitney $U$ test or Wilcoxon signed-rank test. Binomial or ordinal data are expressed as percentages, and comparative univariable analyses were made with the chi-square test, the 2-sided Fisher exact test, or binomial logistic regression, as appropriate.

The effect of the surgical strategy on early mortality was tested by using binomial logistic regression. The results of these multivariate analyses are expressed as odds ratios with $95 \%$ confidence intervals (CIs) for variables with a $P$ value less than.05.

Actuarial survival, freedom from reoperation, and freedom from reintervention were estimated by using the Kaplan-Meier product limit method. These results are expressed as a probability estimate \pm 1 standard error of the mean. The influence of surgical strategies on these actuarial outcome measures have been made with the log-rank test and a stepwise Cox regression analysis. The results of these multivariate analyses are expressed as likelihood ratios (LRs) with $95 \% \mathrm{CI}$ for variables with a $P$ value less than .05 .

\section{Results}

Early mortality for the entire series was $28 \%(n=102)$, and there were 31 late deaths. Actuarial survival was $62 \% \pm 3 \%$ at 6 months after the NP. Early mortality was lower in group C $(15 \%)$ than group A $(31 \%)$ or B $(31 \%, P<.05)$. Early mortality was 2.6 times lower in group $\mathrm{C}$ than group $\mathrm{A}$ or $\mathrm{B}$ on multivariable analysis (odds ratio 0.38; $95 \% \mathrm{CI}$, 0.18-0.78). Actuarial survival at 6 months after the NP (Figure 3, A) was better in group C $(78 \% \pm 5 \%)$ than group $\mathrm{A}(59 \% \pm 5 \%)$ or $\mathrm{B}(58 \% \pm 4 \%, P<.05)$. Actuarial
A

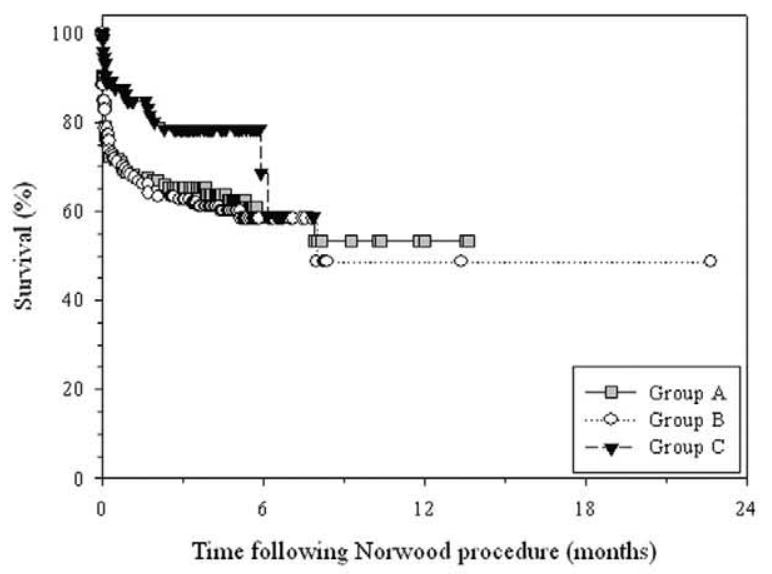

B

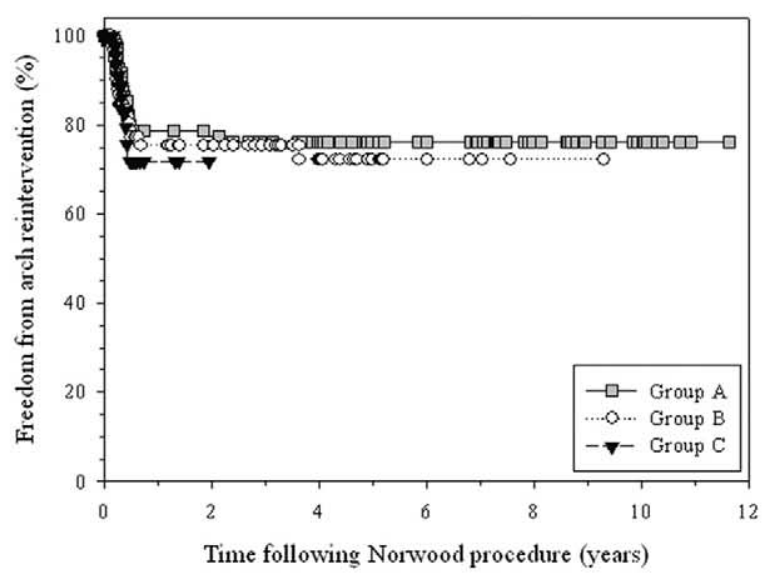

$\mathrm{C}$

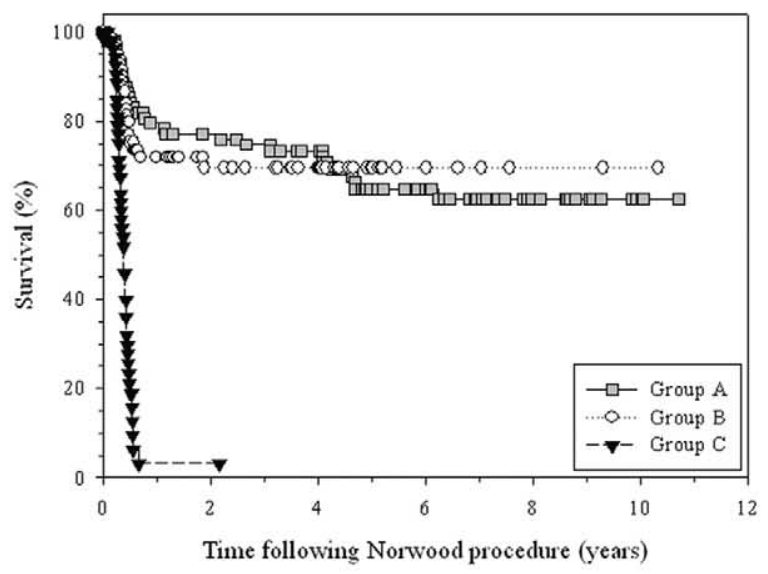

Figure 3. Kaplan-Meier estimated freedom from event after the Norwood procedure. A, Actuarial survival. B, Actuarial freedom from neoaortic arch intervention or reoperation. C, Actuarial freedom from pulmonary artery intervention or reoperation. 
survival in group $\mathrm{C}$ was 2 times better than group $\mathrm{A}$ or $\mathrm{B}$ on multivariable analysis (LR 0.51; 95\% CI, 0.30-0.86).

Fifty-three patients (14\%) had neoaortic arch reintervention. In the majority of cases this was performed by balloon angioplasty. At our institution, reintervention on the neoaortic arch is indicated when the gradient across the arch is more than $10 \mathrm{~mm} \mathrm{Hg}$ during routine catheter insertion before the stage II procedure. Freedom from arch reintervention was $79 \% \pm 4 \%$ at 1 year and $76 \% \pm 4 \%$ at 10 years. Figure $3, B$ illustrates that there was no difference among groups $\mathrm{A}, \mathrm{B}$, and $\mathrm{C}$ on univariable analysis $(P=.71)$. In addition, there was no difference whether the aortic back wall was left in continuity (16\%) or the coarctation was resected completely $(14 \%)(P=.78)$.

Of 367 patients who underwent the NP, 226 (61.5\%) underwent stage II, and 98 (26.7\%) had completion of Fontan circulation (stage III). One hundred patients (27\%) required subsequent CPA patch augmentation at stage II. Freedom from CPA patch augmentation was $61 \% \pm 3 \%$ at 1 year, and was lower in group C $(3 \% \pm 3 \%)$ than group A $(80 \% \pm 4 \%)$ or B $(72 \% \pm 5 \%, P<.05$; Figure $3, C)$. Group $\mathrm{C}$ was more likely to have CPA patch augmentation than group A or B on multivariable analysis (LR 7.41; 95\% CI, 4.73-11.63).

After stage II, 41 patients (18\%) required catheter-based reintervention on CPAs, and almost all were directed to the left pulmonary artery (99\%). Actuarial freedom from catheter-based reintervention was $98 \% \pm 1 \%$ and $72 \% \pm$ $4 \%$ at 1 and 5 years, respectively. Multivariable analysis showed that catheter-based reintervention of the CPAs has become more common with time. Complete duct tissue and coarctation resection independently increased the risk of reintervention of the CPAs (LR 3.9; 95\% CI, 1.6-9.6) after stage II. Arch reconstruction or CPA defect closure techniques did not affect the risk of reoperation or catheterbased reintervention on CPAs.

\section{Discussion}

The management of HLHS continues to present one of the greatest challenges in congenital heart surgery. The optimal surgical management for patients with HLHS remains controversial. Although alternative strategies, such as neonatal orthotopic heart transplantation, have been advocated for these patients, ${ }^{26}$ staged surgical palliation has gained increasing acceptance as the primary treatment option for these patients. ${ }^{7}$ Nevertheless, the NP for HLHS is associated with a high operative mortality, which is substantially higher than that associated with other congenital cardiac defects requiring neonatal repair. In the consensus-based method of risk adjustment for in-hospital mortality among children younger than 18 years after surgery for congenital heart disease (Risk Adjustment for Congenital Heart Surgery-1), ${ }^{27}$ the NP is included in the highest category (cate- gory 6). Many variations of the NP have been described, and the optimum surgical strategy has not been clearly defined. In particular, the type of arch reconstruction technique and source of pulmonary blood flow have been the target areas for considerable debate.

\section{Pulmonary Blood Flow}

There have been numerous variations of the shunt supplying pulmonary blood flow. Initially, there was a tendency to use a central shunt in the belief that it would allow a more uniform growth of CPAs. ${ }^{21}$ The central shunt, however, did not eliminate the problem of distortion of CPAs at the site of insertion, and it could be more difficult to take down. ${ }^{28}$ With the introduction of a smaller 3.5-mm shunt, the use of right-side MBTS became the choice for most surgeons, and it was routinely used at our institution until February 2002.

In 1981, Dr Norwood described a valved or nonvalved conduit from the right ventricle to the distal main pulmonary artery (RV-PA) to supply the pulmonary blood flow. ${ }^{6}$ The RV-PA conduit only gained popularity as an alternative to the right MBTS after the reports of Kishimoto and colleagues ${ }^{29}$ and subsequently Sano and colleagues. ${ }^{22}$ The principal advantage of the RV-PA conduit is that it abolishes the diastolic "runoff" from the systemic to the pulmonary circulation, which characterizes the MBTS. This, in turn, increases diastolic pressure and coronary perfusion pressure. ${ }^{22}$ Abolishing the diastolic "runoff" may also ensure a more stable balance between the systemic and pulmonary circulations, in which systemic and coronary blood flow are less influenced by fluctuations in pulmonary vascular resistance. ${ }^{23}$ A number of authors have highlighted the improved early postoperative hemodynamics associated with the RV-PA conduit compared with the right MBTS. $^{22,23}$

Hughes and colleagues ${ }^{25}$ also identified that the RV-PA conduit was associated with improved early postoperative right ventricular function. In addition, Pizarro and colleagues ${ }^{13}$ suggested that the RV-PA conduit might have a beneficial impact on outcome after the NP. In the present study, the modified NP with an RV-PA conduit was associated with a substantial improvement in early mortality and actuarial survival (Figure 3,A). The use of the RV-PA conduit has become routine at our institution since March 2002.

Although we observed an improvement in the survival after the introduction of RV-PA conduit, we were concerned about the frequency and severity of the CPA stenoses at the site of insertion of the conduit in this group of patients. The majority of these patients required subsequent CPA patch augmentation in contrast with patients in groups $\mathrm{A}$ and $\mathrm{B}$ (Figure 3,C).

We initially considered that this problem might be a technical issue related to the difficulty in sizing the length of 
conduit, which could lead to a distortion in the CPAs. To obviate the problem, we explored the idea of shifting the distal end of RV-PA conduit on the right side of the neoaorta, because the surgical approach to this area is easier and patching of CPAs could be accomplished more easily than on the left side of the aorta.

The RV-PA conduit, on the right side of the ascending aorta, has a longer course, curving over the neoaorta, and comes to lie just behind the sternum, which can pose some problems for the resternotomy. Therefore, a Gore-Tex pericardial membrane has been used routinely to close the pericardium. Despite this change in the technique, used routinely since February 2003, the same proportion of patients required subsequent patch augmentation of CPAs. At 6 months after the NP, the freedom from PA reconstruction was $18 \% \pm 12 \%$ and $22 \% \pm 7 \%$ in the left- and right-sided RV-PA groups, respectively $(P=.98)$.

A recent study performed at our institution ${ }^{30}$ showed that despite an almost constant narrowing at the site of its insertion on the CPAs, the RV-PA conduit seems to provide a better growth of distal pulmonary arteries compared with MBTS. We believe the narrowing that occurs with the RV-PA conduit at the site of conduit insertion is a problem inherent to this technique. However, a right-sided RV-PA conduit offers the additional benefit of operating on the right side of neoaorta, where the Glenn shunt has to be made.

\section{Aortic Arch Reconstruction}

Aortic arch reconstruction techniques have changed from the original description made by Dr Norwood, which involved the creation of neoaorta using the original proximal pulmonary artery anastomosed to the ascending and proximal aortic arch. ${ }^{6}$ In 1986 Jonas and colleagues ${ }^{21}$ adopted a different technique, based on the recognition that more than $80 \%$ of patients had coarctation that could not be dealt with appropriately using the original Norwood technique. This involved patching the proximal descending aorta well beyond the junction with the ductus arteriosus, the arch, and the ascending aorta with allograft arterial wall (pulmonary homograft). The pliability of the allograft patch allowed minimal distortion at the most proximal point of ascending aorta, and interrupted sutures were normally used in this area. This technique has become widely adopted as the standard method of arch reconstruction for HLHS.

In 1995, Bu'Lock and associates ${ }^{18}$ and Fraser and $\mathrm{Mee}^{20}$ reported a technique based on reconstruction of the neoaorta without patch supplementation because of possible disadvantages of the homograft, such as lack of growth, degeneration, and calcification. All duct tissue was excised from the anastomotic site, thus minimizing the risk for recoarctation, and the neoaorta was refashioned by directly anastomosing the proximal pulmonary artery, ascending aorta, and aortic arch with the descending aorta, in a complex Damus-Kaye-Stansel anastomosis.

In 1999, Ishino and colleagues ${ }^{19}$ described our experience with this technique in 120 neonates with HLHS. In $85 \%$ of cases, we were able to reconstruct the arch using a direct aortic anastomosis. However, in 15\%, the arch reconstruction was supplemented with a pulmonary homograft patch. This was primarily in patients in whom undue tension on the arch or its branch arteries was unavoidable, or direct aortic anastomosis caused the arch to become distorted. In particular, the authors determined that a long, diminutive ascending aorta ( $\leq 2.0 \mathrm{~mm}$ in diameter), ductal tissue in the aortic arch with coarctation between the left carotid artery and the left subclavian artery, a long ductus arteriosus with a short descending thoracic aorta, and an aberrant right subclavian artery were contradictions to this technique.

In addition, this direct anastomosis technique seems to be technically demanding and surgeon-specific, requiring several technical adjustments for each individual patient. Therefore in April 1999 we adopted a second technique for arch reconstruction with a homograft patch. This technique has become the routine method at our institution, with minor variations as described earlier.

According to the technique used, the management of coarctation and the duct tissue has changed in accordance with the techniques used to reconstruct the aortic arch. All patients who had a complex Damus-Kaye-Stansel anastomosis had complete excision of the coarctation and ductal tissue. In contrast, aortic arch reconstruction with a homograft patch has allowed more individualized management, leaving the aortic back wall in continuity in those patients in whom the aortic coarctation was judged mild or not present at all.

Statistical analysis did not show any difference in reintervention rate on the neoaortic arch between the 2 techniques (Figure 3, B). Nevertheless, patch augmentation seems to provide a more standardized and easier surgical procedure that could be applied to all patients irrespective of arch morphology and other anatomic abnormalities. Furthermore, this technique allows the surgeon to leave the aortic back wall in continuity in selected cases. This is important to maintain optimal alignment of the neoaortic arch.

Irrespective of the technique used for the neoaorta reconstruction, patients who had complete duct tissue and coarctation excision show a higher rate of catheter-based reintervention after stage II on CPAs and particularly on the left pulmonary artery, probably related to the long-standing compression caused by the anastomoses around the coarctation area.

Routine use of homograft patch supplementation, with or without complete coarctation resection, does not show any difference in causing distortion or compression of the CPAs 
compared with the technique without patch supplementation, as demonstrated by a comparable rate of CPA patch augmentation between groups $\mathrm{A}$ and $\mathrm{B}$ (Figure 3,C).

Considerable care is required to tailor the homograft patch around the arch to avoid redundancy of tissue around very narrow areas like the corner between the aortic arch, descending aorta, and left pulmonary artery, or in the more proximal part of the ascending aorta. This redundant allograft material could degenerate over the time and lead to compression of surrounding structures, particularly CPAs. In contrary, undersizing the patch could lead to residual gradient across the aortic arch. We believe that the use of patch augmentation for the arch guarantees a more reproducible and easier surgical technique. This reproducibility is also important in the learning curve of surgeons who start to deal with HLHS and related anomalies. The pliability of the allograft material allows the surgeon to accommodate the different anatomic variations and sizes of the vessels involved in the anastomosis. We did not experience degeneration or other long-term problems with the homograft patch, as initially suspected. Furthermore, a more extensive reconstruction of the ascending aorta is achievable with the patch technique, which may improve coronary perfusion.

\section{Study Limitations}

This study was designed to determine the influence of 3 different surgical strategies on outcome after the NP. Other variables, including risk factors known to influence the outcome after the NP, were not included in the analysis. The influence of all these variables has been the subject of another recent study from our institution. ${ }^{17}$

\section{Conclusions}

We showed an improvement in survival after the use of an RV-PA conduit, but a greater proportion required subsequent pulmonary artery patch augmentation. The type of arch reconstruction did not affect the incidence of arch reintervention, but we believe that patch augmentation of the arch with or without coarctation resection allows the surgeons the ability to deal with all the variety of anatomic problems encountered in HLHS. It is easier and more reproducible; the allograft material offers excellent quality of pliability and hemostasis, and does not seem to have longterm problems such as shrinking, calcification, or other degenerative changes.

\section{References}

1. Noonan JA, Nadas AS. The hypoplastic left heart syndrome: an analysis of 101 cases. Pediatr Clin North Am. 1958;5:1029-56.

2. Von Rueden TJ, Knight L, Moller JH, Edwards JE. Coarctation of the aorta associated with aortic valvular atresia. Circulation. 1975;52: 951-4.

3. Murdison KA, Baffa JM, Farrell PE Jr, Chang AC, Barber G, Norwood WI, et al. Hypoplastic left heart syndrome. Outcome after initial reconstruction and before modified Fontan procedure. Circulation. 1990;82(Suppl):IV199-207.

4. Hawkins JA, Doty DB. Aortic atresia: morphologic characteristics affecting survival and operative palliation. J Thorac Cardiovasc Surg. 1984;88:620-6.

5. Norwood WI, Lang P, Hansen DD. Physiologic repair of aortic atresiahypoplastic left heart syndrome. N Engl J Med. 1983;308:23-6.

6. Norwood WI, Kirklin JK, Sanders SP. Hypoplastic left heart syndrome. Experience with palliative surgery. Am J Cardiol. 1980;45:8791.

7. Pearl JM, Nelson DP, Schwartz SM, Manning PB. First-stage palliation for hypoplastic left heart syndrome in the twenty-first century. Ann Thorac Surg. 2002;73:331-9.

8. Azakie A, Merklinger SL, McCrindle BW, Van Arsdell GS, Lee KJ, Benson LN, et al. Evolving strategies and improving outcomes of the modified Norwood procedure: a 10-year single-institution experience. Ann Thorac Surg. 2001;72:1349-53.

9. Bove EL, Lloyd TR. Staged reconstruction for hypoplastic left heart syndrome. Contemporary results. Ann Surg. 1996;224:387-94.

10. Gaynor JW, Mahle WT, Cohen MI, Ittenbach RF, DeCampli WM, Steven JM, et al. Risk factors for mortality after the Norwood procedure. Eur J Cardiothorac Surg. 2002;22:82-9.

11. Kern JH, Hayes CJ, Michler RE, Gersony WM, Quaegebeur JM. Survival and risk factor analysis for the Norwood procedure for hypoplastic left heart syndrome. Am J Cardiol. 1997;80:170-4.

12. Weinstein S, Gaynor JW, Bridges ND, Wernovsky G, Montenegro LM, Godinez RI, et al. Early survival of infants weighing 2.5 kilograms or less undergoing first-stage reconstruction for hypoplastic left heart syndrome. Circulation. 2003;108(Suppl):II155-60.

13. Pizarro C, Malec E, Maher KO, Januszewska K, Gidding SS, Murdison KA, et al. Right ventricle to pulmonary artery conduit improves outcome after stage I Norwood for hypoplastic left heart syndrome. Circulation. 1999; 100:II167-70.

14. Breymann T, Kirchner G, Blanz U, Cherlet E, Knobl H, Meyer H, et al. Results after Norwood procedure and subsequent cavopulmonary anastomoses for typical hypoplastic left heart syndrome and similar complex cardiovascular malformations. Eur J Cardiothorac Surg. 1999;16:117-24.

15. Tweddell JS, Hoffman GM, Mussatto KA, Fedderly RT, Berger S, Jaquiss RD, et al. Improved survival of patients undergoing palliation of hypoplastic left heart syndrome: lessons learned from 115 consecutive patients. Circulation. 2002;106(Suppl):I82-9.

16. Sano S, Ishino K, Kawada M, Honjo O. Right ventricle-pulmonary artery shunt in first-stage palliation of hypoplastic left heart syndrome. Semin Thorac Cardiovasc Surg Pediatr Card Surg Annu. 2004;7:22-31.

17. McGuirk SP, Griselli M, Stumper O, Rumball E, Miller P, Dhillon R, et al. Staged surgical management of hypoplastic left heart syndrome: a single-institution 12-year experience. Heart. 2005;6 [Epub ahead of print].

18. Bu'Lock FA, Stumper O, Jagtap R, Silove ED, De Giovanni JV, Wright JG, et al. Surgery for infants with a hypoplastic systemic ventricle and severe outflow obstruction: early results with a modified Norwood procedure. Br Heart J. 1995;73:456-61.

19. Ishino K, Stumper O, De Giovanni JJ, Silove ED, Wright JG, Sethia B, et al. The modified Norwood procedure for hypoplastic left heart syndrome: early to intermediate results of 120 patients with particular reference to aortic arch repair. J Thorac Cardiovasc Surg. 1999;117: 920-30.

20. Fraser CD Jr, Mee RB. Modified Norwood procedure for hypoplastic left heart syndrome. Ann Thorac Surg. 1995;60(6 Suppl):S546-9.

21. Jonas RA, Lang P, Hansen D, Hickey P, Castaneda AR. First-stage palliation of hypoplastic left heart syndrome. The importance of coarctation and shunt size. J Thorac Cardiovasc Surg. 1986;92:6-13.

22. Sano S, Ishino K, Kawada M, Arai S, Kasahara S, Asai T, et al. Right ventricle-pulmonary artery shunt in first-stage palliation of hypoplastic left heart syndrome. J Thorac Cardiovasc Surg. 2003;126:504-9.

23. Mair R, Tulzer G, Sames E, Gitter R, Lechner E, Steiner J, et al. Right ventricular to pulmonary artery conduit instead of modified BlalockTaussig shunt improves postoperative hemodynamics in newborns after the Norwood operation. [See comment.] J Thorac Cardiovasc Surg. 2003;126:1378-84. 
24. Malec E, Januszewska K, Kolcz J, Mroczek T. Right ventricle-topulmonary artery shunt versus modified Blalock-Taussig shunt in the Norwood procedure for hypoplastic left heart syndrome-influence on early and late haemodynamic status. Eur J Cardiothorac Surg. 2003; 23:728-33.

25. Hughes ML, Shekerdemian LS, Brizard CP, Penny DJ. Improved early ventricular performance with a right ventricle to pulmonary artery conduit in stage 1 palliation for hypoplastic left heart syndrome: evidence from strain Doppler echocardiography. Heart. 2004;90:191-4.

26. Razzouk AJ, Chinnock RE, Gundry SR, Johnston JK, Larsen RL, Baum MF, et al. Transplantation as a primary treatment for hypoplastic left heart syndrome: intermediate-term results. Ann Thorac Surg. 1996; 62:1-7.

27. Jenkins KJ, Gauvreau K, Newburger JW, Spray TL, Moller JH, Iezzoni LI. Consensus-based method for risk adjustment for surgery for congenital heart disease. J Thorac Cardiovasc Surg. 2002;123: 110-8.

28. Jonas RA. Management of hypoplastic left heart syndrome. Semin Thorac Cardiovasc Surg. 1994;6(1):28-32.

29. Kishimoto H, Kawahira Y, Kawata H, Miura T, Iwai S, Mori T. The modified Norwood palliation on a beating heart. J Thorac Cardiovasc Surg. 1999;118:1130-2.

30. Rumball EM, McGuirk SP, Stümper O, Laker SJ, de Giovanni JV, Wright JCG, et al. The RV-PA conduit stimulates better growth of the pulmonary arteries in hypoplastic left heart syndrome. Eur J Cardiothorac Surg. 2005;5:801-6.

\section{Discussion}

Dr Thomas L. Spray (Philadelphia, Pa). I think this excellent presentation has demonstrated quite a large experience with HLHS with various modifications of the standard NP. The most recent experience with the RV-PA shunt modification suggests an improved survival with this newer technique. Our own experience presented from the Children's Hospital of Philadelphia in a contemporaneous group comparing these 2 strategies, however, did not show any difference in early mortality or interstage mortality. So I think one of the real limitations of this study is the fact that this is a sequential comparison rather than a contemporaneous comparison, and one would hope, at least, that all our results improve over time.

Because this is not a contemporaneous comparison of different techniques, I wonder if you would comment if there were any changes in the operative strategies or the postoperative management in these patients that might be contemporaneous with the switch to the RV-PA shunt. I noticed, for example, that your use of retrograde cerebral perfusion was almost contemporaneous with that transition. Do you think this might have some impact on your overall outcome?

Dr Griselli. Thank you, Dr Spray, for your remarks and question. In terms of changes of technique, there really is no major difference in what I explained in terms of surgical techniques and shunt management. The population has not changed in the last 10 years in terms of numbers or pathologies. In view of the antenatal diagnosis, we see more patients undergoing surgery who are more stable and in better shape than they were in the past. So it has probably been modified because of the population.

In terms of postoperative care, as in any branch of medicine, there has been some improvement. But I believe that as we manage the patient in the Children's Hospital together with intensivists, the RV-PA conduit presents the patient in a completely different condition than previously. The patients are much more stable, the management of inotropic support is much easier, and the fluid management is much easier. So I think, yes, there have been some improvements in postoperative management, but I believe we also offer to intensivists a big difference in terms of patients, in terms of stability.

So I think this is difficult, of course, to extrapolate to what is more important or if it has been an influence. But I believe that we also have given them a much more stable patient. As we are involved in the treatment of these patients, and having the luxury to look at both types of the NP, I believe that has been a fundamental step forward.

Dr Spray. Other studies have suggested that anatomic and genetic factors have a major influence on overall outcome and mortality for this operation. You mentioned you had a high percentage of standard HLHS in this overall population, but you really didn't compare the distribution of anatomies, birth weights, and other risk factors over the various time frames of the study. If you did look at that, do you think they would be evenly distributed, or do you think there has been an increase, for example, or a decrease recently in more complex anatomies, low birth weights, and other issues, since you, as you mentioned, have patients with a prenatal diagnosis more commonly?

Dr Griselli. No, there has not been a difference. We just finished a study on a risk model for an NP and the banding of children, and there was no difference in terms of pathologies, and that could occur in this program; basically it could alter what we found in this study. So I don't think that was an important factor. Other problems we found, but not the pathologies, have been changed in the last 10 years.

Dr Spray. I was struck by the fact that despite your improved early survival, the interstage mortality was virtually identical in all of the different parts of your series, dating back even to the earliest portion of the series, and that would make me wonder whether the hemodynamic benefits that are ascribed to the RV-PA shunt do not really impact significantly on coronary perfusion or potential sudden death out of hospital. Would you comment on that? Why do you think the interstage mortality is so high?

Dr Griselli. The interstage mortality has not changed. This is one of the issues we are trying to address. As you said, if this RV-PA conduit makes the children much more stable soon after surgery, then maybe they are more fragile than the others. And we found there is no statistical difference in patients who had an RV-PA conduit undergoing the second stage earlier than the other groups.

And the other problem is that some of the patients coming to Children's may be not local. We may be lacking some infrastructure to do surveillance on these children soon after surgery. We should improve in that sense. We had the stepladder improvement every year, even with other techniques in terms of early mortality, but it seems not to be going so well in the long term. It should improve in terms of looking after these patients better, after the first month I would say.

Dr Spray. I thought it was interesting that when you compare the techniques of arch reconstruction, whether you resect the coarctation or not, whether you patch the aorta or not, the incidence of reintervention on the aorta seems to be fairly consistent among the various groups. So it would suggest that resection of coarctation is not really necessary if you patch the aortic arch, and yet resection of coarctation was associated with left pulmonary artery stenosis. It seems unusual that leaving coarctation tissue in 
place would not increase the risk of reintervention with balloon dilation of the aortic arch, but you did not find that. I wonder if you would comment on that?

Dr Griselli. At the beginning of the study we thought that we would find more incidence of recoarctation or more risk of reballooning the arch than with the other technique. But this has not happened. I believe that was described in 1998 in a meeting by the same institution. The resection of coarctation was supposed to be fundamental in the treatment of hypoplasty and not use any material because otherwise it will calcify and degenerate. We now have experience showing no difference in the 2 groups even after 10 years of further experience. So I think that is what we are seeing.

We surprise ourselves as well. I thought there would be more. It doesn't surprise me that maybe leaving the coarctation alone doesn't create less incidence of balloon stent on the pulmonary artery, particularly on the left side. We have seen basically $98 \%$ of the cases. So we were surprised with the results of this.

Dr Spray. Just 1 final question. If you see so much PA narrowing with the RV-PA shunt, and you virtually always have to patch the pulmonary arteries, which is certainly our experience also, I wonder whether you think it would be advisable to routinely patch the pulmonary artery bifurcation at the time of the first stage of operation if you're going to have to do that anyway? Do you think this is a fundamental issue with the way the connection is made, and maybe we should change, again, the way we do these operations to decrease the risk of stenosis?

Dr Griselli. Yes, certainly. We've now committed that if we are going to perform an RV-PA conduit, we think that at the next stage we definitely are going to patch. So we believe it is correct and connected to the techniques. And that's why, believing that we have to do this patching, we shifted the conduit to the right side where we have to do the Glenn shunt, so it's easier to approach anyway.

Patching at the first stage has been tried in terms of local patch where the shunt is going to be, but still results in a narrowing on the subsequent angiogram.

Dr Spray. I enjoyed this study very much and look forward to the results of a randomized prospective trial that compares these 2 operations to try to get at the answer of whether we really are fundamentally changing the pathophysiology of this condition.

Dr S. Sano (Okayama, Japan). Congratulations on your excellent results in this huge series.

Our series on the CPA construction after an RV-PA shunt has acquired very few patients. We used the pericardium in the first 11 patients as a patch, and then we found that a lot of patients became stenotic. Then we changed to the Gore-Tex cuff (29 cases), and since then we found only 1 or 2 patients who required CPA construction. So I think there are technical things.

\section{Authoritative}

The Journal of Thoracic and Cardiovascular Surgery is the most frequently cited thoracic/cardiovascular surgery journal in the Science Citation Index. An article in JTCVS is cited on average almost twice as often as those in the closest cardiothoracic journal. 